\title{
Changes in Lipids of Young and Adult Saury Cololabis saira (Pisces)
}

\author{
T. Ota ${ }^{1}$, T. Takagi ${ }^{1}$ and S. Kosaka ${ }^{2}$ \\ ${ }^{1}$ Faculty of Fisheries, Hokkaido University, Hakodate, Japan \\ 2 Tohoku Regional Fisheries Research Laboratory, Shlogama, Miyagl Prefecture, Japan
}

\begin{abstract}
Class and fatty acid compositions of the lipids were investigated in young and adult saury Cololabis saira from the northwestern Pacific Ocean. In the flesh of young fish during northward migration, lipid contents were about $3 \%$. Adults in the feeding period contained more than 15\% lipid contents in August (males) and September (females). In adult flesh, the lipid contents decreased gradually during southward migration and reached about $4 \%$ in late November. Triglycerides in flesh lipids increased with lipid accumulation. Wax esters occurred mainly as a minor component in flesh lipids of saury during the feeding period. Fatty acids of adult non-polar lipids contained more 20:1 and 22:1 than those of juveniles. These acids increased gradually during southward migration and reached $24.7 \%$ for $20: 1$ and $32.8 \%$ for $22: 1$ in late November. On the other hand, $16: 0,16: 1,18: 1$ and $18: 4 \omega 3$ tended to decrease. These fluctuations in lipd may be related not only to dietary lipids but also to the utilization of lipids by the fish for migration and gonadal maturation.
\end{abstract}

\section{INTRODUCTION}

The biology of saury Cololabis saira, as related to fisheries' interests in the northeastern seas of Japan, has been investigated in numerous studies because the saury is one of the most important local resources. Tsuchiya et al. (1953) studied the chemical components of saury during different fishing seasons and found that fat contents were inversely proportional to moisture contents, and that fat plus moisture contents remained constant at about $80 \%$ of the meat weight throughout the experimental period. Hata and Tashiro (1953) described the relation between calorific value, body size and fishing season. Nagakura (1956) reported high fat contents at the beginning of the fishing season decreased toward the end of it. Ito and Fukuzumi (1962) and Shimma and Taguchi (1964) analyzed the fatty acid composition of saury oil and compared their data with those of other fish oils. Ackman (1963) revealed the occurrence of $4,7,10,13,16$ docosapentaenoic acid in commercial saury oil.

The present paper deals with variations in lipid class and fatty acid compositions of saury during young and adult stages, in order to assess the ecological significance of changes in lipids.

\section{MATERIALS AND METHODS}

The Cololabis saira used in this study were taken by a stick-held dip net from northwestern Pacific Ocean waters in 1973 and 1974. Several males and females of uniform size were selected for analyses. After measuring body length and weight, the flesh lipids of each fish were extracted by employing the method of Bligh and Dyer (1959). The livers were pooled and extracted with identical procedures.

Flesh and liver lipids were separated into non-polar lipids and polar lipids by silicic acid-celite 545 (2:1 w/ w) column chromatography using chloroform and methanol as solvents. Each lipid fraction was saponified with $1 \mathrm{~N}$ alcoholic $\mathrm{KOH}$ solution. The recovered fatty acids were then esterified with $14 \% \mathrm{BF}_{3}$ in methanol.

Gas-liquid chromatography of fatty acid methyl esters was carried out on a Yanagimoto gas chromatograph (G80) equipped with a hydrogen flame ionization detector. Two columns (1.5 $\mathrm{m}$ in length, $3 \mathrm{~mm}$ i.d.) packed with $5 \%$ DEGS on Chromosorb WAW-DMCS (100-120 mesh) and 10\% DEGS on Chromosorb WAW (80-100 mesh) were used. For analysis, the column temperature was programmed from $155^{\circ}$ to $210^{\circ} \mathrm{C}$, at 
$4{ }^{\circ} \mathrm{C}$ min $^{-1}$, using a $5 \%$ DEGS column. It was maintained at $190^{\circ} \mathrm{C}$ using $10 \%$ DEGS column. Injector and detector temperature were $240^{\circ} \mathrm{C}$. A digital integrator (Shimadzu ITG-4AX) was applied to determine peak areas.

The thin-layer chromatographic system proposed by Downing (1968) was followed for separation and quantification of classes of non-polar lipids. They were separated by a three-step development on a silica gel plate (Wakogel B-5, $0.25 \mathrm{~mm}$ thickness). The solvents used were $n$-hexane at the first step; benzene at the second; and n-hexane : diethyl ether : acetic acid (70:30:1 by vol.) at the third step. After development, the individual spots were visualized by spraying with $50 \% \mathrm{H}_{2} \mathrm{SO}_{4}$ and heating at $180^{\circ} \mathrm{C}$ for $90 \mathrm{~min}$. Quantification of each spot was carried out on a photoden- sitometer (Ozumer OZ-82D). Triglycerides and free fatty acids containing small amounts of partial glycerides were isolated from non-polar lipids by preparative thin-layer chromatography on a silica gel plate (Wakogel B-10,0.5 mm thickness) with benzene. After spraying the plate with $0.1 \%$ ethanolic rhodamine $B$, the corresponding bands were scraped off and extracted with diethyl ether. The fatty acids from each fraction were esterified with $14 \% \mathrm{BF}_{3}$ in methanol.

\section{RESULTS}

The lipid contents in the flesh of young Cololabis saira during their northward migratory period ranged from 2.8 to $3.4 \%$. Values for adults (No. 5) during this

Table 1. Cololabis saira. Dates and locations of sampling, body sizes, and lipid contents in flesh and liver

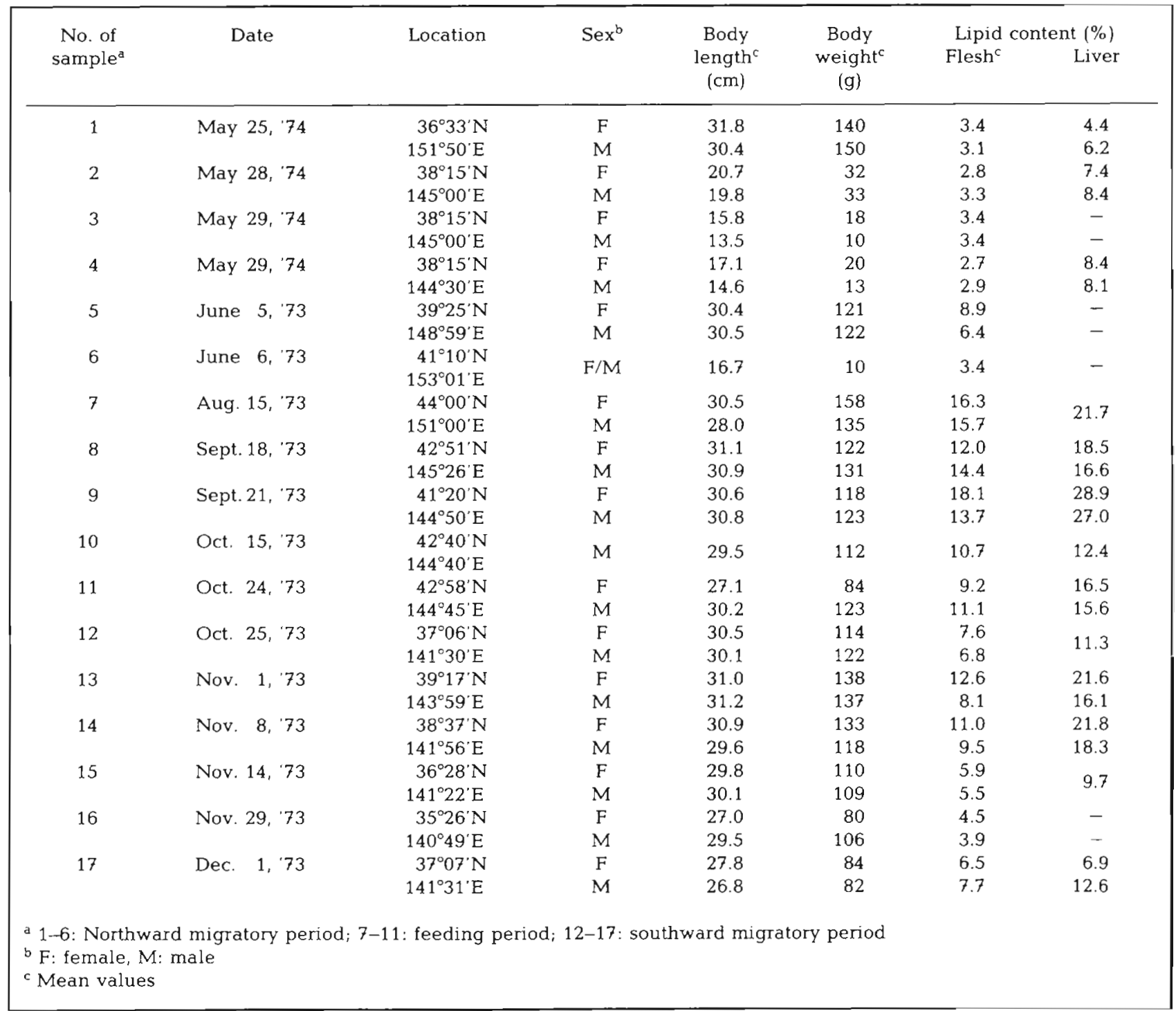


period were somewhat higher: $6.4 \%$ for males and $8.9 \%$ for females (June), than those for adults (No. 1) taken in May (Table 1). These results indicate differences in the ability to recover from spawning and overwintering conditions. Flesh lipid contents of adult fish during the feeding period (August-October) exceeded $10 \%$. Throughout the experiment, the highest value for males occurred in August, that for females in September. During the southward migratory period, flesh lipid contents decreased gradually down to $3.9 \%$ in males and $4.5 \%$ in females in late November. Livers contained always larger amounts of lipids than flesh from the same lot. The sequential changes in the amount of flesh lipids were also observed for the liver.

The progressive decrease of flesh lipid contents during southward migration may be correlated not only to the decrease in the amount of food (about $10 \%$ of that available during the feeding period; Odate, 1977) in this sea area, but also to gonadal maturation. In addition, a slightly faster reduction in lipid contents of male flesh was observed. This indicates that males in general mature prior to females.

The lipids of young fish during the northward migratory period contained more sterol esters and phospholipids than those of adults during the feeding period (Table 2). During the feeding period, the flesh lipids contained much more triglycerides, representing about $80 \%$ of the total lipids. The triglycerides tended to decrease gradually during a period of southward migration, whereas free fatty acids and free sterols increased. Wax ester - minor components in the flesh lipids during the feeding period - were not detected during the pre-spawning period (November-October).

The fatty acid composition of non-polar lipids in flesh are shown in Tables 3 and 4 . In adults, fatty acid composition of flesh lipids taken during the feeding and southward migratory period paralleled approximately the results reported by Ito and Fukuzumi (1962), Ackman (1963) and Shimma and Taguchi (1964), establishing as major fatty acids: 14:0, 16:0,

Table 2. Cololabis saira. Lipid class composition of flesh lipids (expressed as \% of total lipids)

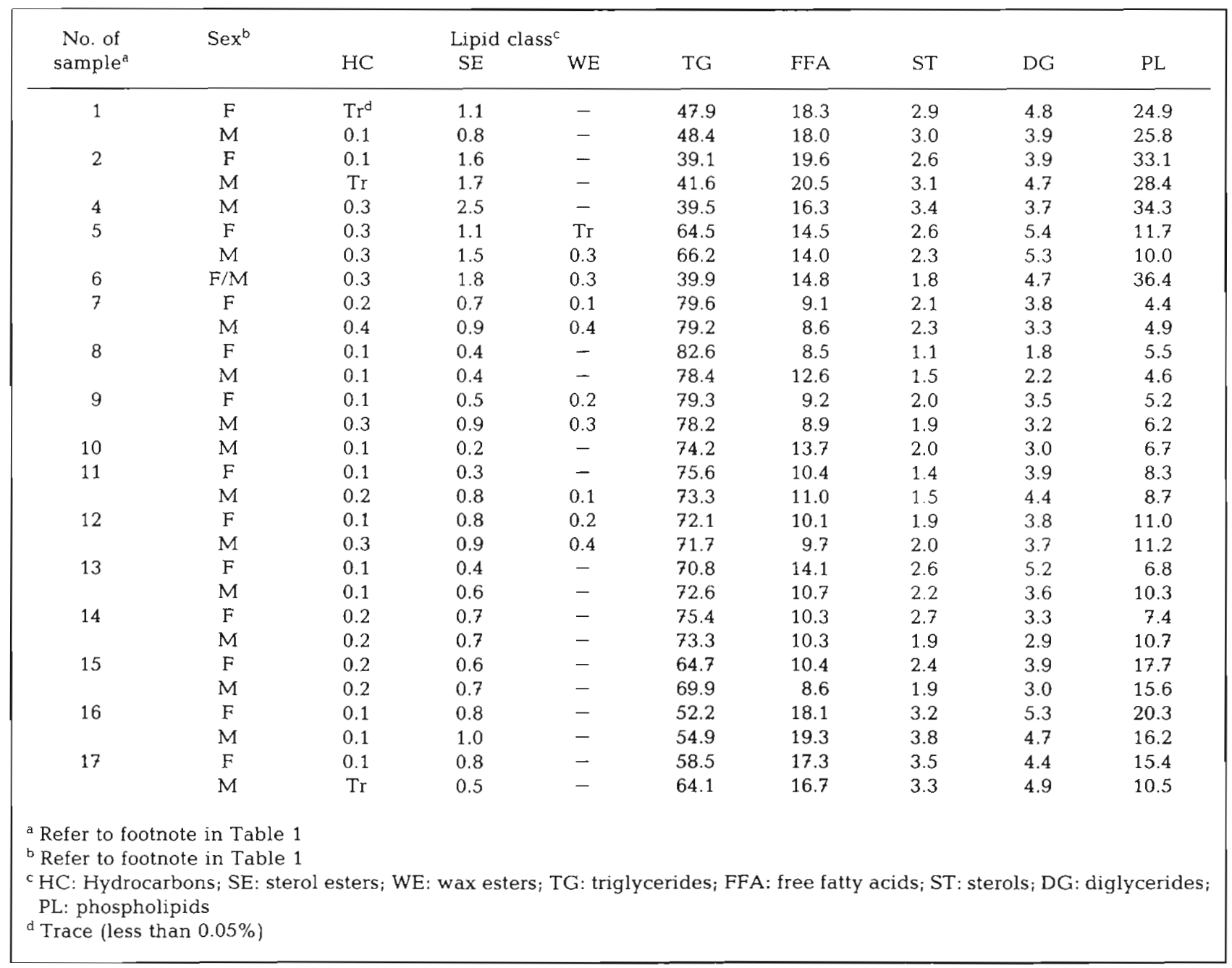


Table 3. Cololabis saira. Composition of major fatty acids of non-polar lipids in female flesh (\%)

\begin{tabular}{|c|c|c|c|c|c|c|c|c|c|c|c|c|c|c|c|}
\hline \multirow[t]{2}{*}{ Fatty acid } & \multicolumn{4}{|c|}{ May } & \multirow{2}{*}{$\frac{\text { June }}{5}$} & \multirow{2}{*}{$\frac{\text { Aug. }}{7}$} & \multicolumn{2}{|c|}{ Sept. } & \multicolumn{2}{|c|}{ Oct. } & \multicolumn{4}{|c|}{ Nov. } & \multirow{2}{*}{$=\frac{\text { Dec. }}{17}$} \\
\hline & $1^{b}$ & 2 & 3 & 4 & & & 8 & 9 & $\overline{11}$ & $\overline{12}$ & $\overline{13}$ & 14 & 15 & 16 & \\
\hline $14: 0$ & 5.1 & 5.8 & 5.6 & 5.1 & 7.8 & 12.1 & 11.2 & 10.5 & 9.9 & 9.9 & 7.5 & 9.3 & 9.6 & 8.1 & 6.4 \\
\hline $16: 0$ & 22.2 & 26.7 & 25.6 & 22.2 & 21.3 & 16.3 & 15.2 & 13.6 & 15.1 & 13.4 & 12.5 & 14.0 & 12.3 & 12.1 & 9.8 \\
\hline $17: 0$ & 1.2 & 1.1 & 1.0 & 1.0 & 0.1 & 0.4 & 0.3 & 0.6 & 0.6 & 0.5 & 0.3 & 0.7 & 0.9 & 0.4 & 0.3 \\
\hline $18: 0$ & 6.7 & 7.3 & 7.0 & 4.9 & 4.6 & 1.5 & 1.3 & 1.5 & 1.6 & 1.7 & 1.9 & 2.3 & 2.2 & 2.2 & 1.9 \\
\hline $16: 1$ & 5.4 & 5.6 & 5.2 & 5.3 & 6.1 & 6.9 & 5.7 & 4.9 & 5.0 & 4.4 & 4.7 & 4.7 & 3.8 & 4.7 & 3.6 \\
\hline $18: 1$ & 10.5 & 9.5 & 9.4 & 9.0 & 8.0 & 6.3 & 5.4 & 6.2 & 5.8 & 6.1 & 6.6 & 6.7 & 5.8 & 6.2 & 5.3 \\
\hline $20: 1$ & 6.5 & 4.7 & 6.3 & 8.6 & 8.4 & 15.1 & 17.3 & 16.6 & 18.9 & 18.2 & 18.0 & 15.4 & 18.5 & 18.3 & 20.2 \\
\hline $22: 1$ & 6.6 & 5.8 & 6.0 & 10.9 & 9.3 & 15.7 & 16.1 & 17.6 & 20.3 & 22.0 & 19.9 & 19.7 & 20.6 & 24.8 & 28.0 \\
\hline $24: 1$ & 1.7 & 1.5 & 1.6 & 1.5 & 0.7 & 0.8 & 1.1 & 1.0 & 1.0 & 1.8 & 1.8 & 1.4 & 2.3 & 2.1 & 2.0 \\
\hline $18: 2 \omega 6$ & 1.1 & 1.4 & 1.2 & 1.5 & 1.4 & 1.7 & 1.2 & 1.5 & 1.2 & 1.1 & 1.3 & 1.3 & 1.2 & 1.1 & 1.0 \\
\hline $18: 3 \omega 3$ & 0.4 & 0.6 & 0.4 & 0.2 & 1.0 & 1.6 & 1.2 & 1.2 & 0.3 & 0.3 & 0.2 & 0.9 & 0.5 & 0.2 & 0.3 \\
\hline $18: 4 \omega 3$ & 2.0 & 2.2 & 2.3 & 2.4 & 3.5 & 4.4 & 4.2 & 5.0 & 3.4 & 2.4 & 3.4 & 3.5 & 2.9 & 1.7 & 3.0 \\
\hline $20: 4 \omega 3$ & 0.5 & 0.4 & 0.4 & 0.6 & 0.9 & 1.2 & 1.5 & 1.5 & 1.2 & 0.7 & 1.0 & 1.6 & 1.4 & 0.6 & 0.9 \\
\hline $20: 5 \omega 3$ & 7.1 & 6.7 & 6.8 & 7.3 & 7.8 & 3.5 & 5.7 & 4.8 & 5.3 & 5.3 & 5.9 & 4.4 & 4.1 & 4.5 & 4.1 \\
\hline $22: 5 \omega 3$ & 2.0 & 1.2 & 1.4 & 1.3 & 1.8 & 1.0 & 1.3 & 1.1 & 0.1 & 1.0 & 1.5 & 1.1 & 1.6 & 1.4 & 1.2 \\
\hline $22: 6 \omega 3$ & 17.8 & 16.0 & 15.6 & 14.9 & 11.8 & 6.6 & 6.0 & 6.8 & 5.7 & 6.5 & 10.3 & 7.1 & 8.3 & 8.8 & 8.7 \\
\hline Total saturated acids: & 36.0 & 42.1 & 40.8 & 34.3 & 35.2 & 31.5 & 29.4 & 27.5 & 29.0 & 26.8 & 23.2 & 27.7 & 26.0 & 23.8 & 19.1 \\
\hline Total mono-unsaturated acids: & 31.7 & 27.8 & 29.5 & 36.5 & 33.9 & 45.8 & 46.4 & 47.3 & 51.7 & 53.3 & 51.8 & 48.8 & 51.7 & 56.8 & 59.7 \\
\hline Total poly-unsaturated acids: & 32.2 & 30.1 & 29.7 & 29.3 & 30.9 & 22.7 & 24.2 & 25.2 & 19.3 & 19.9 & 25.1 & 23.5 & 22.3 & 19.4 & 21.1 \\
\hline \multicolumn{16}{|c|}{$\begin{array}{l}\text { a Other acids - including } 12: 0 \text {, Iso } 15: 0,15: 0, \text { Iso } 16: 0,14: 1,17: 1,19: 1,16: 2 \omega 7,16: 4 \omega 3,16: 4 \omega 1,20: 2 \omega 6,20: 3 \omega 6,20: 4 \omega 6,21: 5 \omega 3 \\
\text { and } 22: 5 \omega 6 \text { - were detected as minor components representing less than } 1 \% \text { of the total fatty acids } \\
\text { bo. of sample }\end{array}$} \\
\hline
\end{tabular}

Table 4. Cololabis saira. Composition of major fatty acids of non-polar lipids in male flesh (\%)

\begin{tabular}{|c|c|c|c|c|c|c|c|c|c|c|c|c|c|c|c|c|c|}
\hline \multirow[t]{2}{*}{ Fatty acid ${ }^{a}$} & \multicolumn{4}{|c|}{ May } & \multicolumn{2}{|c|}{ June } & \multirow{2}{*}{$\frac{\text { Aug. }}{7}$} & \multicolumn{2}{|c|}{ Sept. } & \multicolumn{3}{|c|}{ Oct. } & \multicolumn{4}{|c|}{ Nov. } & \multirow{2}{*}{$\frac{\text { Dec }}{17}$} \\
\hline & $\overline{1^{b}}$ & 2 & 3 & $\overline{4}$ & 5 & $6^{c}$ & & 8 & 9 & 10 & 11 & $\overline{12}$ & 13 & 14 & 15 & $\overline{16}$ & \\
\hline $14: 0$ & 5.5 & 6.6 & 5.6 & 5.4 & 8.7 & 7.5 & 11.1 & 10.0 & 10.9 & 11.9 & 13.0 & 10.5 & 11.8 & 9.3 & 10.4 & 7.9 & 8.1 \\
\hline $16: 0$ & 20.3 & 25.7 & 22.4 & 22.8 & 19.1 & 19.8 & 15.6 & 15.5 & 15.0 & 13.6 & 14.9 & 13.9 & 12.4 & 11.9 & 10.5 & 8.5 & 12.6 \\
\hline $17: 0$ & 1.2 & 1.1 & 1.2 & 1.0 & 0.9 & 1.2 & 0.4 & 0.6 & 0.6 & 1.0 & 0.7 & 0.5 & 0.2 & 0.4 & 1.0 & 0.2 & 0.2 \\
\hline $18: 0$ & 5.8 & 6.8 & 6.0 & 5.2 & 3.1 & 3.9 & 1.5 & 1.8 & 1.5 & 1.4 & 1.5 & 1.9 & 1.7 & 1.5 & 1.5 & 1.7 & 1.8 \\
\hline $16: 1$ & 5.2 & 6.0 & 5.4 & 5.4 & 6.4 & 5.5 & 6.1 & 5.9 & 5.3 & 4.8 & 5.2 & 5.2 & 4.7 & 4.4 & 3.2 & 3.7 & 5.1 \\
\hline $18: 1$ & 8.9 & 8.7 & 7.9 & 8.7 & 5.9 & 6.0 & 5.6 & 5.9 & 6.1 & 5.1 & 6.2 & 7.8 & 5.5 & 5.5 & 4.5 & 4.4 & 5.7 \\
\hline $20: 1$ & 6.8 & 4.8 & 5.7 & 8.0 & 9.4 & 9.7 & 15.0 & 14.6 & 14.8 & 17.3 & 18.3 & 18.7 & 19.2 & 20.8 & 21.4 & 24.7 & 18.6 \\
\hline $22: 1$ & 8.4 & 7.7 & 7.5 & 9.8 & 12.2 & 14.5 & 15.5 & 13.9 & 17.7 & 19.1 & 19.4 & 18.8 & 21.3 & 24.6 & 27.9 & 32.8 & 22.3 \\
\hline $24: 1$ & 2.1 & 1.5 & 1.5 & 1.6 & 0.9 & 1.4 & 1.0 & 1.4 & 1.6 & 2.0 & 0.7 & 1.7 & 1.6 & 1.5 & 1.7 & 2.0 & 1.7 \\
\hline $18: 2 \omega 6$ & 1.1 & 0.9 & 1.5 & 1.3 & 1.8 & 1.3 & 1.5 & 1.5 & 1.5 & 1.2 & 1.2 & 1.2 & 0.9 & 1.0 & 0.9 & 0.7 & 0.8 \\
\hline $18: 3 \omega 3$ & 0.2 & 0.3 & 0.2 & 0.3 & 1.0 & 0.6 & 1.3 & 1.2 & 0.9 & 0.8 & 0.2 & 0.8 & 0.1 & 0.3 & 0.3 & 0.2 & 0.1 \\
\hline $18: 4 \omega 3$ & 2.5 & 2.2 & 2.6 & 2.9 & 2.7 & 2.8 & 5.1 & 4.4 & 4.4 & 3.3 & 3.3 & 2.7 & 3.4 & 2.6 & 2.5 & 1.4 & 2.5 \\
\hline $20: 4 \omega 3$ & 0.7 & 0.3 & 0.6 & 0.5 & 1.0 & 1.5 & 1.2 & 1.2 & 1.2 & 1.2 & 0.8 & 1.7 & 1.1 & 0.8 & 0.9 & 0.5 & 0.9 \\
\hline $20: 5 \omega 3$ & 7.1 & 6.7 & 7.3 & 7.3 & 8.7 & 6.8 & 6.4 & 6.1 & 5.1 & 4.6 & 4.8 & 5.0 & 4.0 & 4.0 & 2.9 & 2.4 & 5.9 \\
\hline $22: 5 \omega 3$ & 2.4 & 1.1 & 1.5 & 1.3 & 1.6 & 1.4 & 1.0 & 1.5 & 1.4 & 1.7 & 0.7 & 1.6 & 1.1 & 1.0 & 1.1 & 1.3 & 1.5 \\
\hline $22: 6 \omega 3$ & 18.5 & 14.7 & 18.0 & 15.0 & 10.5 & 12.8 & 7.1 & 7.7 & 7.0 & 6.5 & 4.6 & 3.5 & 8.1 & 6.0 & 5.9 & 5.3 & 8.8 \\
\hline Total saturated acids: & 33.8 & 42.7 & 37.2 & 35.6 & 33.1 & 33.5 & 30.0 & 29.6 & 29.4 & 29.2 & 31.8 & 28.1 & 27.0 & 24.4 & 24.5 & 18.8 & 23.7 \\
\hline Total mono-unsaturated acids: & 32.3 & 29.7 & 29.3 & 34.5 & 35.9 & 38.1 & 44.0 & 42.6 & 46.4 & 49.1 & 50.6 & 53.0 & 53.1 & 57.6 & 59.7 & 68.1 & 54.2 \\
\hline Total poly-unsaturated acids: & 34.1 & 27.4 & 33.4 & 30.0 & 30.9 & 28.4 & 26.0 & 27.8 & 24.2 & 21.7 & 17.6 & 18.8 & 19.9 & 18.0 & 15.8 & 12.9 & 22.1 \\
\hline${ }^{*}$ Refer to footnote in Table 3 & & & & & & & & & & & & & & & & & \\
\hline befer to footnote in Table 3 & & & & & & & & & & & & & & & & & \\
\hline 'Contains female flesh lipids & & & & & & & & & & & & & & & & & \\
\hline
\end{tabular}




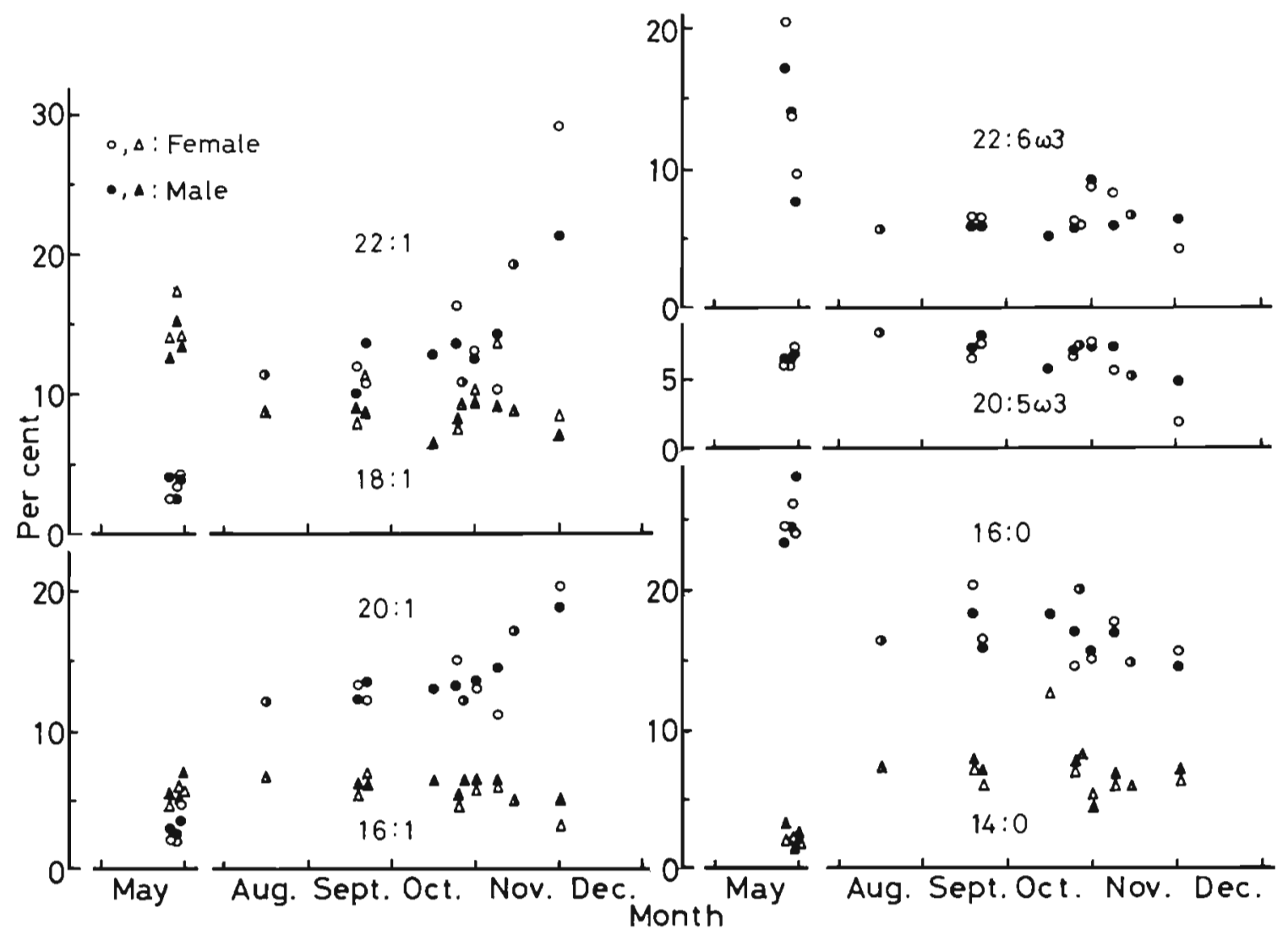

Fig. 1. Cololabis saira. Variations of major fatty acids of non-polar lipids in saury liver

Table 5. Cololabis saira. Fatty acid composition of lipid fractions of saury flesh (\%)

\begin{tabular}{|c|c|c|c|c|c|c|c|}
\hline Fatty acid & $\mathrm{TG}^{\mathrm{a}}$ & $\mathrm{FFA}^{a}$ & $\mathrm{PL}^{\mathrm{a}}$ & Fatty acid & TG & FFA & PL \\
\hline \multicolumn{4}{|c|}{ Saturated acids } & \multicolumn{4}{|c|}{ Poly-unsaturated acids } \\
\hline $12: 0$ & $\operatorname{Tr}^{b}$ & 0.1 & $T_{T}$ & $16: 2 \omega 7$ & 0.1 & 0.7 & 0.2 \\
\hline $14: 0$ & 9.9 & 7.6 & 1.8 & $16: 4 \omega 3$ & 0.1 & 0.5 & $\operatorname{Tr}$ \\
\hline Iso $15: 0$ & 0.3 & 0.6 & $\operatorname{Tr}$ & $16: 4 \omega 1$ & 0.3 & 0.1 & 0.1 \\
\hline $15: 0$ & 0.3 & 0.4 & 0.2 & $18: 2 \omega 6$ & 0.3 & 0.5 & 0.2 \\
\hline Iso $16: 0$ & $\operatorname{Tr}$ & 0.1 & $\mathrm{~T} \tau$ & $18: 3 \omega 3$ & 0.4 & 0.2 & 0.2 \\
\hline $16: 0$ & 7.7 & 8.6 & 23.7 & $18: 4 \omega 3$ & 0.4 & 0.4 & $\operatorname{Tr}$ \\
\hline $17: 0$ & 0.1 & 0.6 & 0.6 & $20: 2 \omega 6$ & 0.1 & 0.1 & 0.2 \\
\hline $18: 0$ & 1.4 & 1.8 & 8.5 & $20: 3 \omega 6$ & $\operatorname{Tr}$ & $\operatorname{Tr}$ & Tr \\
\hline \multirow[t]{3}{*}{ Total } & 19.7 & 19.8 & 34.8 & $20: 4 \omega 3$ & $\operatorname{Tr}$ & 0.2 & 0.1 \\
\hline & & & & $20: 5 \omega 3$ & 2.1 & 3.1 & 4.5 \\
\hline & \multicolumn{3}{|c|}{ Mono-unsaturated acids } & $21: 5 \omega 3$ & $\operatorname{Tr}$ & 1.8 & Tr \\
\hline $14: 1$ & 0.1 & 0.7 & 0.2 & $22: 5 \omega 6$ & Tr & $\operatorname{Tr}$ & 0.4 \\
\hline $16: 1$ & 3.2 & 5.4 & 1.7 & $22: 5 \omega 3$ & 1.2 & 1.9 & 2.0 \\
\hline $17: 1^{\mathrm{c}}$ & 0.2 & 0.2 & 0.1 & $22: 6 \omega 3$ & 3.0 & 7.0 & 40.6 \\
\hline $18: 1$ & 4.2 & 5.0 & 4.4 & Total & 8.0 & 16.6 & 48.5 \\
\hline $19: 1$ & $\operatorname{Tr}$ & 0.1 & 0.1 & & & & \\
\hline $20: 1$ & 27.0 & 22.5 & 4.5 & & & & \\
\hline $22: 1$ & 35.6 & 28.6 & 5.9 & & & & \\
\hline $24: 1$ & 2.0 & 1.7 & $\operatorname{Tr}$ & & & & \\
\hline Total & 72.3 & 63.7 & 16.7 & & & & \\
\hline \multicolumn{8}{|c|}{$\begin{array}{l}\text { a TG: Triglycerides; FFA: free fatty acids; PL: phospholipids } \\
\text { b Trace (less than } 0.05 \% \text { ) } \\
\text { ' Includes } 16: 2 \omega 4\end{array}$} \\
\hline
\end{tabular}


$16: 1,18: 1,20: 1,22: 1,20: 5 \omega 3$ and $22: 6 \omega 3$. The fatty acid composition of flesh lipids during northward migration differed clearly from those in individuals obtained during other periods. The major differences in fatty acid contents were as follows: 14:0,20:1 and 22:1 were lower, while 16:0, 20:5 13 were higher than those recorded during other periods. During the southward migratory period, non-polar lipids of males tended to contain more $20: 1$ and $22: 1$, but less $20: 5 \omega 3$ and $22: 6 \omega 3$ than those of females.

Fatty acids indicating maximum variation were $20: 1$ and 22:1. These acids increased with decreasing lipid contents of the flesh during southward migration. On

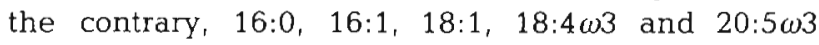
tended to decrease. Especially, flesh lipids from males caught in late November revealed to highest amount of $20: 1(24.7 \%)$ and $22: 1(32.8 \%)$. When comparing the fatty acid composition of lipids in liver and flesh, it becomes clear that liver lipids contain relatively high amounts of $16: 0,16: 1,18: 1$ and $20: 5 \omega 3$, but low amounts of $14: 0,20: 1$ and 22:1. Fluctuations similar to those in 20:1 and 22:1 of flesh lipids were also observed in liver (Fig. 1). The fatty acid composition of lipid fractions in male flesh lipids in late November (No. 16) are shown in Table 5. Triglycerides and free fatty acids contained much more 20:1 and 22:1 than phospholipids which were rich in 16:0 and 22:6 13 .

\section{DISCUSSION}

During the feeding period in the cold current Oyashio region, Cololabis saira mainly feeds on copepods such as Calanus cristatus and C. plumchrus (Hotta and Odate, 1956). As is well known, some copepod species contain large amounts of wax esters as energy reserve instead of triglycerides (Lee et al., 1971b; Benson et al., 1972; Kayama et al., 1976). Takahashi and Yamada (1976) examined the lipid composition of seven species of crustacean plankters and found that C. plumchrus contained $68 \%$ wax esters and $7 \%$ triglycerides in its total lipids; the major fatty alcohols found in wax esters were alc $20: 1$ and alc 22:1; these represented more than $60 \%$ of the total.

While it may be suggestive that such dietary lipid composition may considerably influence the lipid composition of saury and that saury accumulate wax esters, in flesh lipids, wax esters ranged only from 0.4 to $1.0 \%$ during the feeding period. On the other hand, triglycerides containing high amounts of $20: 1$ and $22: 1$ acids represented the dominant lipid class.

In marine animals, biosynthesis and metabolism of wax esters have been studied by many investigators (e. g. Lee et al., 1970, 1971a; Nevenzel, 1970; Sand et al., 1971, 1973). In fishes, hydrolysis of wax esters occurs in the intestinal tract, and the released fatty alcohols are oxidized to fatty acids (Rahn et al., 1973). The high concentration of long-chain mono-unsaturated acids (20:1 and 22:1) in non-polar lipids of saury flesh suggests that the resulting fatty acids further reesterified into triglycerides. It is presumed that the digestive lipase concerned with the hydrolysis of wax esters in saury would be more active during the feeding period than during other stages of migration (Patton et al., 1975).

During the southward migratory period, some changes in fatty acid composition of saury lipids were observed. These variations may be related to the selective utilization of fatty acids as energy source rather than to influx from dietary sources. Our results indicate that $16: 0,16: 1$ and $18: 1$ acids are utilized selectively for migration and gonadal maturation, while longchain mono-unsaturated acids $(20: 1$ and $22: 1)$ remain without decomposition and are stored in the lipids. As shown in Table 5, the relatively high contents of 16:0, 16:1 and 18:1 and the low contents of long-chain mono-unsaturated acids in the free fatty acids, as compared with the triglycerides, may also represent a phenomenen related to the selective utilization of fatty acids by fishes (Krueger et al., 1968; Saddler et al., 1972; Hayashi and Takagi, 1977).

In recent years, the influences of docosenoic acids (22:1) on mammalian organs have attracted the attention of many researchers. Results of studies on function and metabolism of this acid in each organ were described elsewhere (Beare-Rogers, 1977; Takagi, 1978). Ackman and Loew $(1977 a, b)$ revealed that the skeletal and cardiac muscle of the cynomolgus monkeys Macaca fascicularis fed diets containing high levels of fat rich in docosenoic acids (erucic acid or cetoleic and cetelaidic acids) showed lipidosis. In Canada, the content of docosenoic acid in the total fatty acids of edible oil products is restricted to $5 \%$ or less.

It is well known that the docosenoic acid is one of the major components in fatty acids of certain marine lipids and plant oil such as rapeseed oil (Takagi, 1978). Since saury lipids also contain much docosenoic acid, this species should be caught when the content of docosenoic acid in the lipids is low.

Acknowledgements. The authors wish to thank Messrs K. Sakamoto and T. Yamazaki for their assistance in the experimental work.

\section{LITERATURE CITED}

Ackman, R. G. (1963). On the occurrence of 4,7,10,13,16docosapentaenoic acid in saury (Cololabis saira) oil. J. Fish. Res. Bd Can. 20: 1551-1552 
Ackman, R. G., Loew, F. M. (1977a). The effects of high levels of fats rich in erucic acid (from rapeseed oil) or cetoleic and cetelaidic acids (from partially hydrogenated fish oil) in a short-term study in a non-human primate species I. Fette Seifen Anstr.-Mittel 79: 15-24

Ackman, R. G., Loew, F. M. (1977b). The effects of high levels of fats rich in erucic acid (from rapeseed oil) or cetoleic and cetelaidic acids (from partially hydrogenated fish oil) in a short-term study in a non-human primate species II. Fette Seifen Anstr.-Mittel 79: 58-69

Beare-Rogers, J. L. (1977). Docosenoic acids in dietary fats. Prog. Chem. Fats 15: 29-56

Benson, A. A., Lee, R. F., Nevenzel, J. C. (1972). Wax esters: Major marine metabolic energy sources. In: Ganguly, J., Smellie, R. M. S. (eds) Current trends in the biochemistry of lipids. Academic Press, New York and London, pp. 175-187

Bligh, E. G., Dyer, W. J. (1959). A rapid method of total lipid extraction and purification. Can. J. Biochem. Physiol. 37: 911-917

Downing, D. T. (1968). Photodensitometry in the thin-layer chromatographic analysis of neutral lipids. J. Chromat. 38: 91-99

Hata, M., Tashiro, M. (1953). Biochemical studies on skipper (Cololabis saira) - II. Moisture and crude fat content. Bull. Japan. Soc. Sci. Fish. 19: 518-524

Hayashi, K., Takagi, T. (1977). On the fatty acid composition of fish affected by excessive stress. Bull. Japan. Soc. Sci. Fish. 43: 1189-1194

Hotta, H., Odate, K. (1956). The food and feeding habits of saury, Cololabis saira. Bull. Tohoku Reg. Fish. Res. Lab. 7: $60-69$

Ito, S., Fukuzumi, K. (1962). Quantitative analysis of fatty acid esters of marine animal oils by gas-liquid chromatography. Kogyo Kagaku Zassi 65: 1963-1968

Kayama, M., Ikeda, Y., Komaki, T. (1976). Studies on the lipids of marine zooplankton, with special reference to wax ester distribution in crustaceans and its in vivo formation. Yukagaku 25: 329-334

Krueger, H. M., Saddler, J. B., Chapman, G. A., Tinsley, I. J., Lowry, R. R. (1968). Bioenergetics, exercise, and fatty acids of fish. A.m. Zool. 8: 119-129

Lee, R. F., Nevenzel, J. C., Paffenhöfer, G.-A., Benson, A. A. (1970). The metabolism of wax esters and other lipids by the marine copepod, Calanus helgolandicus. J. Lipid Res. 11: $237-240$

Lee, R. F., Hirota, J., Barnet, A. M. (1971a). Distribution and importance of wax esters in marine copepods and other zooplankton. Deep Sea Res. 18: 1147-1165

Lee, R. F., Nevenzel, J. C., Paffenhöfer, G.-A. (1971b). Importance of wax esters and other lipids in the marine food chain: phytoplankton and copepods. Mar. Biol. 9: 99-108

Nagakura, K. (1956). The variation of the fat content of saury, Cololabis saira, in the north-eastern sea area of Japan. Bull. Tohoku Reg. Fish. Res. Lab. 7: 54-59

Nevenzel, J. C. (1970). Occurrence, function and biosynthesis of wax esters in marine organisms. Lipids 5: 308-319

Odate, K. (1977). On the feeding habits of the pacific saury, Cololabis saira (Brevoort). Bull. Tohoku Reg. Fish. Res. Lab. 38: 75-88

Patton, J. S., Nevenzel, J. C., Benson, A. A. (1975). Specificity of digestive lipases in hydrolysis of wax esters and triglycerides studied in anchovy and other selected fish. Lipids 10: $575-583$

Rahn, C. H., Sand, D. M., Schlenk, H. (1973). Wax esters in fish: Metabolism of dietary palmitate in the gourami (Trichogaster cosby). J. Nutr. 103: 1441-1447

Saddler, J. B., Koski, K. V., Cardwell, R. D. (1972). Fatty acid alterations during migration and early sea water growth of chum salmon (Oncorhynchus keta). Lipids 7: 90-95

Sand, D. M., Hehl, J. L., Schlenk, H. (1971). Wax esters in fish: Turnover of oleic acid in wax esters and triglycerides of gouramis. Lipids 6: 562-566

Sand, D. M., Rahn, C. H., Schlenk, H. (1973). Wax esters in fish: Absorption and metabolism of oleyl alcohol in the gourami (Trichogaster cosby). J. Nutr. 103: 600-607

Shimma, Y., Taguchi, H. (1964). A comparative study on fatty acid composition of fish. Bull. Japan. Soc. Sci. Fish. 30: 179-188

Takagi, T. (1978). Progress in the studies on docosenoic acids. Yukagaku 27: 123-135

Takahashi, H., Yamada, M. (1976). Lipid composition of seven species of crustacean plankton. Bull. Japan. Soc. Sci. Fish. 42: 769-776

Tsuchiya, Y., Hata, M., Asano, M., Takahashi, I., Nomura, T., Suzuki, Y. (1953). Biochemical studies on skipper (Cololabis saira) - I. General component. Bull. Japan. Soc. Sci. Fish. 19: 513-517 